Article

\title{
Anti-Corrosion Property of Glass Flake Reinforced Chemically Bonded Phosphate Ceramic Coatings
}

\author{
Ge Yan ${ }^{1}$, Mingyang Wang ${ }^{2}$, Tao Sun ${ }^{3, * \mathbb{C}}$, Xinping $\mathrm{Li}^{1}{ }^{1}$, Guiming Wang ${ }^{3}$ and Weisong Yin ${ }^{1}$ \\ 1 School of Civil Engineering and Architecture, Wuhan University of Technology, Wuhan 430070, China \\ 2 State Key Laboratory for Disaster Prevention \& Mitigation of Explosion \& Impact, \\ Army Engineering University, Nanjing 210007, China \\ 3 State Key Laboratory of Silicate Materials for Architectures, Wuhan University of Technology, \\ Wuhan 430070, China \\ * Correspondence: sunt@whut.edu.cn
}

Received: 23 May 2019; Accepted: 26 June 2019; Published: 28 June 2019

\begin{abstract}
Glass flake (GF) was used as the reinforcement in chemically bonded phosphate ceramic (CBPC) coatings to promote anti-corrosion property. The crystalline phase, curing behavior, micromorphology and electrochemical performance of the coatings were studied. The results indicate that with the addition of magnesia $(\mathrm{MgO})$, a new bonding phase $\left(\mathrm{Mg}_{3}\left(\mathrm{PO}_{4}\right)_{2}\right)$ can be formed, which can help the CBPCs achieve a more compact and denser structure. The effect of the magnesia and the GF additives on curing behavior is obvious: the heat of reaction of the phosphate ceramic materials increases with the addition of the magnesia and the GF, which emphasizes the higher crosslinking density in the phosphate ceramic materials. The phosphate ceramic coatings with the magnesia have a higher impedance value compared with the neat phosphate ceramic coating, while the highest impedance value is obtained with increased content of GF. The corrosion mechanism is mainly contributed by the new bonding phase and GF particles, which can hinder the permeation pathway and make the permeation more circuitous.
\end{abstract}

Keywords: anti-corrosion property; glass flake; chemically bonded phosphate ceramic (CBPC); corrosion mechanism

\section{Introduction}

Reinforced concrete (RC) is one of the most commonly used modern construction materials. The corrosion of the interface between concrete and steel rebar affects the service life of RC seriously. In the past decades, in order to increase the lifespan of $\mathrm{RC}$, researchers have dedicated efforts towards the enhancement of bond strength and corrosion resistance in RC [1,2]. Among all the anti-corrosion technology, a most effective way to improve the property of corrosion resistance is to cover the rebar with a durable and adhesive coating [3], which can be divided into organic coatings and inorganic coatings. Epoxy $[4,5]$ and modified resin [6] have been generally adopted as organic coatings, while inorganic coatings include galvanizing metal coatings [7], chemically reactive enamel (CRE) coatings [8], and chemically bonded phosphate ceramic (CBPC) coatings [9]. In the application of the epoxy coating in reinforced concrete, Brown MC [10] arrived at the conclusion that the durability of the steel with the epoxy coating was not ideal due to the moisture that penetrates beneath the coating, which means that the epoxy-coated steel has a higher corrosion rate than bare steel. What's more, the bone strength loss between the epoxy-coated steel and the concrete reached 20\% compared to bare rebar [11]. For the inorganic coatings, a weakening effect on the bond strength between the galvanized reinforcing steel and the concrete was observed due to hydrogen evolution at the interface [12]. A high temperature of $800^{\circ} \mathrm{C}$ needs to be applied to the chemically reactive enamel-coated steel, which can lead to a reduction in the creep limit and strength [1]. 
In recent years, more and more studies have focused on the utilization of CBPCs, which are derived from the reactions between base and acid, such as the metal oxide $\left(\mathrm{Al}_{2} \mathrm{O}_{3}, \mathrm{MgO}\right)$ and the soluble acid phosphate $\left(\mathrm{KH}_{2} \mathrm{PO}_{4}, \mathrm{Al}\left(\mathrm{H}_{2} \mathrm{PO}_{4}\right)_{3}\right)[13,14]$. Due to their corrosion resistance, mechanical resistance, thermal conductivity and low temperature used in their processing, CBPC coatings have considerable technological importance [15]. CBPC coatings can be seen to use the phosphate matrixes as the binding phases and the metal oxides as suitable fillers. Researchers [16-18] have investigated the influence of ceramic oxides $\left(\mathrm{AlN}, \mathrm{MgO}\right.$, and $\mathrm{ZrO}_{2}$ ) on the improvement of the thermal properties of CBPC coatings. The abrasive filler of $\mathrm{Al}_{2} \mathrm{O}_{3}-\mathrm{SiC}$ in aluminum phosphate has been produced to enhance the abrasion resistance of coatings [19]. The ceramic coatings of aluminum phosphate formed by the reaction between soluble acid phosphates and alumina and alumina-sol-gel systems was studied [20]. H.M. Hawthorne et al. [21] prepared phosphate ceramic coatings on stainless steel substrates and analyzed the mechanical performance and electrochemical property. The application by thermal spraying for binders was carried out, and the microstructure defects of the coatings were improved [22]. A series of CBPC coatings were applied to steel surfaces to reduce or eliminate corrosion [23]. Da Bian et al. [24] paid attention to graphene-reinforced CBPC coatings. Zhu Ding et al. [25] studied the mechanical characterization and microstructure of $C B P C$ composites reinforced with fiber, prepared at room temperature.

Glass flake (GF) particles are inorganic platelets with excellent resistance to chemicals and aging. Many efforts have been focused towards corrosion-resistant coatings with the advanced barrier properties of GF [26-30], and the parallel and overlapped arrangement of GF particles could form a compact impermeable layer in organic coatings. There are microstructure defects between GF particles and the organic coating matrix due to the coating matrix belonging to organic material, while GF belongs to inorganic materials; thus, we can only effectively improve the permeability resistance of organic coatings by surface treatment and functionalization of GF particles.

In all cases cited, there have been few reports on the application of GF particles as fillers in CBPC coatings. Meanwhile, the anticorrosion mechanism of the GF-reinforced CBPC coatings also needs to be illustrated. In this study, CBPC coatings reinforced with GF particles were prepared in order to protect the round steel. The crystalline phase, curing behavior, and micromorphology of the CBPC-based ceramic materials were analyzed, and the electrochemical characterization of the CBPC coatings was carried out in $3.5 \mathrm{wt} . \% \mathrm{NaCl}$ solution using electrochemical measurement. Furthermore, the anticorrosion mechanism of the coating was also investigated.

\section{Materials and Methods}

\subsection{Materials}

The CBPC coatings reinforced with GF were applied onto round steel $8 \mathrm{~mm}$ in diameter and $20 \mathrm{~mm}$ in length by mixing raw materials of phosphate ceramic materials as shown in Table 1.

Table 1. Raw material of phosphate ceramic materials.

\begin{tabular}{ccc}
\hline Name & Chemical Formula & Manufacturer \\
\hline Monoaluminium phosphate & $\mathrm{Al}^{\left(\mathrm{H}_{2} \mathrm{PO}_{4}\right)_{3}}$ & - \\
Chromium trioxide & $\mathrm{CrO}_{3}$ & Sinopharm Chemical Reagent Co., Ltd., Shanghai, China \\
Alumina & $\mathrm{Al}_{2} \mathrm{O}_{3}$ & Aladdin Industrial Corporation Tech Co., Ltd., Shanghai, China \\
Magnesia & $\mathrm{MgO}$ & Sinopharm Chemical Reagent Co., Ltd., Shanghai, China \\
Glass flake (150 mesh) & $\mathrm{SiO}_{2}$ & Hebei Huawei Glass Flake Co., Ltd., Langfang, China \\
\hline
\end{tabular}

The preparation of monoaluminium phosphate (MAP) binder is based on the reaction between aluminum hydroxide and phosphoric acid at $120^{\circ} \mathrm{C}$ under constant stirring for $60 \mathrm{~min}$. The quantities were calculated according to Equation (1). For the preparation of MAP binder, $135.1 \mathrm{~g}$ of pure water were used to dilute $345.9 \mathrm{~g}$ of $85 \%$ phosphoric acid to $60 \%$, and then $78.0 \mathrm{~g}$ of aluminum hydroxide were added. 


$$
3 \mathrm{H}_{3} \mathrm{PO}_{4}+\mathrm{Al}(\mathrm{OH})_{3} \rightarrow \mathrm{Al}\left(\mathrm{H}_{2} \mathrm{PO}_{4}\right)_{3}+3 \mathrm{H}_{2} \mathrm{O}
$$

The mixture proportion of phosphate ceramic coating materials are shown in Table 2. The coated samples were prepared by brush coating with a clean bristle brush. Before preparing coating, 800 grit silicon carbide abrasive papers were used to polish the surface of the round steel, the round steel was degreased in acetone for $15 \mathrm{~min}$ (in ultrasonic bath) and then rinsed with deionized water. The coated round steel was placed at room temperature $\left(25 \pm 1^{\circ} \mathrm{C}\right)$ for $10 \mathrm{~h}$ and then heated in an electric oven according to the curing process as shown in Figure 1.

Table 2. Mixture proportion of phosphate ceramic coating pastes.

\begin{tabular}{cccccc}
\hline \multirow{2}{*}{ Sample } & \multirow{2}{*}{ MAP (g) } & \multicolumn{3}{c}{ Powders (g) } & \multirow{2}{*}{$\mathbf{H}_{\mathbf{2}} \mathbf{O}(\mathbf{g})$} \\
& & $\mathbf{A l}_{\mathbf{2}} \mathbf{O}_{\mathbf{3}}$ & $\mathbf{M g O}$ & $\mathbf{G F}$ & \\
\hline CBPC & 10.0 & 10.0 & - & - & 5.0 \\
GCBPC0 & 10.0 & 9.5 & 0.5 & 0 & 5.0 \\
GCBPC5 & 10.0 & 9.0 & 0.5 & 0.5 & 5.0 \\
GCBPC10 & 10.0 & 8.5 & 0.5 & 1.0 & 5.0 \\
GCBPC15 & 10.0 & 8.0 & 0.5 & 1.5 & 5.0 \\
\hline
\end{tabular}

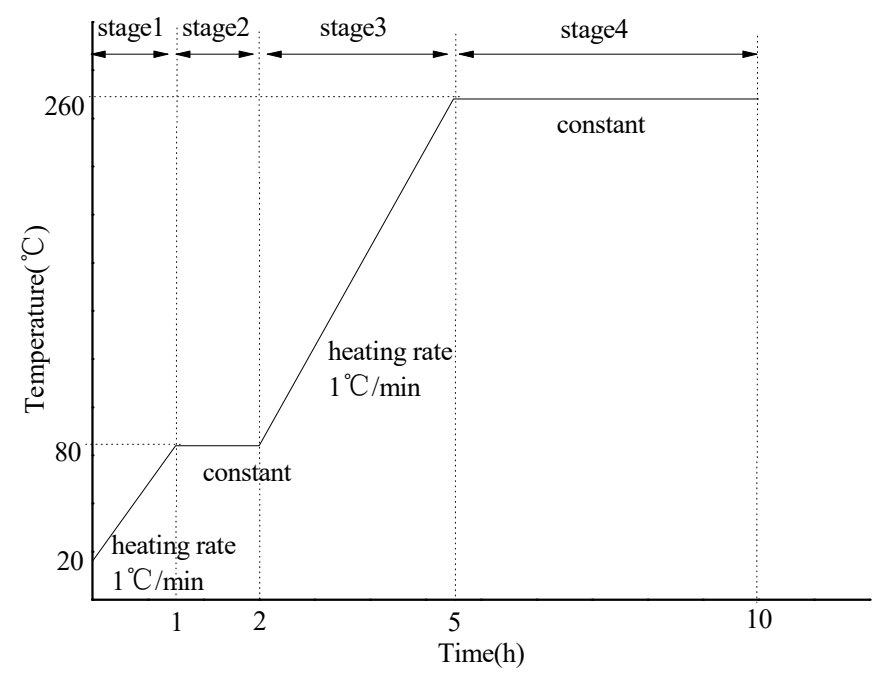

Figure 1. Curing process of phosphate ceramic coatings.

\subsection{Characterization}

Laser scanning confocal microscopy (LSCM, manufacture, Oberkochen, Germany) was used to characterize the thickness and surface topography of GF. The thickness of the coating was tested using a QNIX4500 coating thickness gauge measurement (QNIX, Oberkochen, Germany) at a precision of $1 \mu \mathrm{m}$. The crystalline phases of phosphate ceramic coatings after curing were measured by X-ray diffractometer (PANalytical Empyrean, Almelo, The Netherlands) using a $\mathrm{CuK} \alpha$ source scanning from $5^{\circ}$ to $70^{\circ}$ in $2 \theta$. A differential scanning calorimeter (STA instruments, Selb, Germany) was used to analyze the curing behavior of phosphate ceramic coating materials under $\mathrm{N}_{2}$ atmosphere with gas flow of $30 \mathrm{~mL} / \mathrm{min}$, heat velocity of $10{ }^{\circ} \mathrm{C} / \mathrm{min}$, start temperature $25^{\circ} \mathrm{C}$ and end temperature $400{ }^{\circ} \mathrm{C}$. Furthermore, the SEM micrographs of the surface and cross-section of the coated samples were investigated on a JSM-IT300 (JEOL, Tokyo, Japan) under secondary electron mode, test voltage of $10 \mathrm{kV}$ and surface treatment with platinum.

The potentiodynamic polarization was conducted using a workstation CS350 (Wuhan Corrtest Instrument Co., Ltd., Wuhan, China), as well as the electrochemical impedance spectroscopy (EIS) measurement, with a three-electrode system, containing the reference electrode (saturated calomel electrode), the counter electrode (platinum electrode), and the working electrode (sample). 
The electrochemical experiment was conducted in $3.5 \mathrm{wt} . \% \mathrm{NaCl}$ solution at $25 \pm 1^{\circ} \mathrm{C}$. The exposed surface area was around $2.5 \mathrm{~cm}^{2}$. After the samples were immersed in the $\mathrm{NaCl}$ solution for $10 \mathrm{~h}$, the potentiodynamic polarization was performed at a speed of $2 \mathrm{mV} \cdot \mathrm{s}^{-1}$, from $-100 \mathrm{mV}$ to $100 \mathrm{mV}$. EIS measurements were carried out with AC signals of $5 \mathrm{mV}$ peak-to-peak amplitude in the frequency start at $100 \mathrm{kHz}$ and end at $0.01 \mathrm{~Hz}$. Z-View software was used to evaluate the EIS data. At least three repeated electrochemical tests were carried out to confirm the reliability of the measurement.

\section{Results and Discussions}

\subsection{Characterization of GF}

As shown in Figure 2, the GF, with 150 mesh, has an average thickness of 3-4 $\mu \mathrm{m}$ and an average particle size of $105 \mu \mathrm{m}$. Meanwhile, the GF is irregularly formed and has a smooth surface topography. The amorphous peaks of GF in the XRD patterns were observed in the range of $15-40^{\circ}$, as can be seen in Figure 3, which means the GF particles are silica-based materials with a wide typical diffraction peak [31].
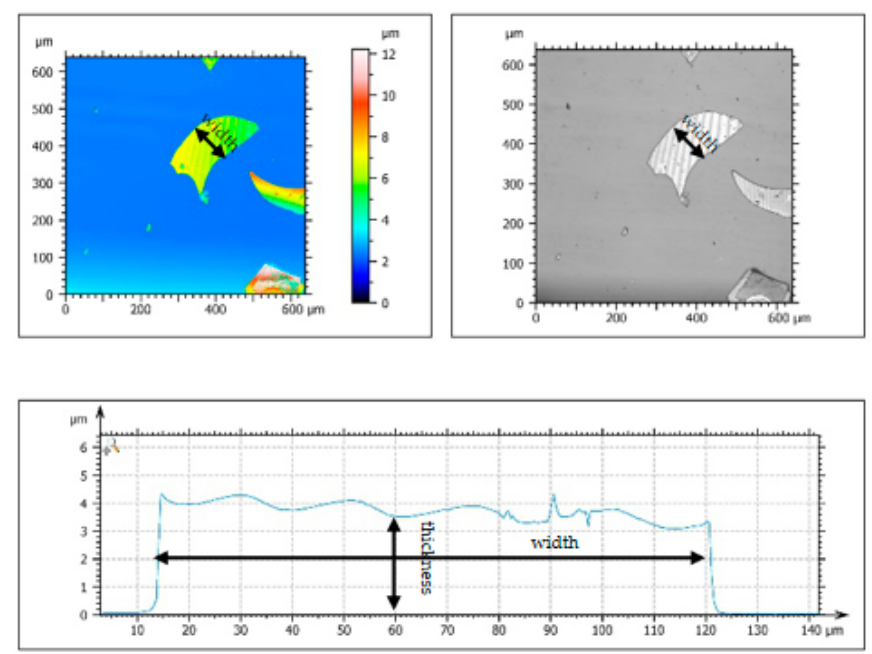

Figure 2. Surface topography of GF.

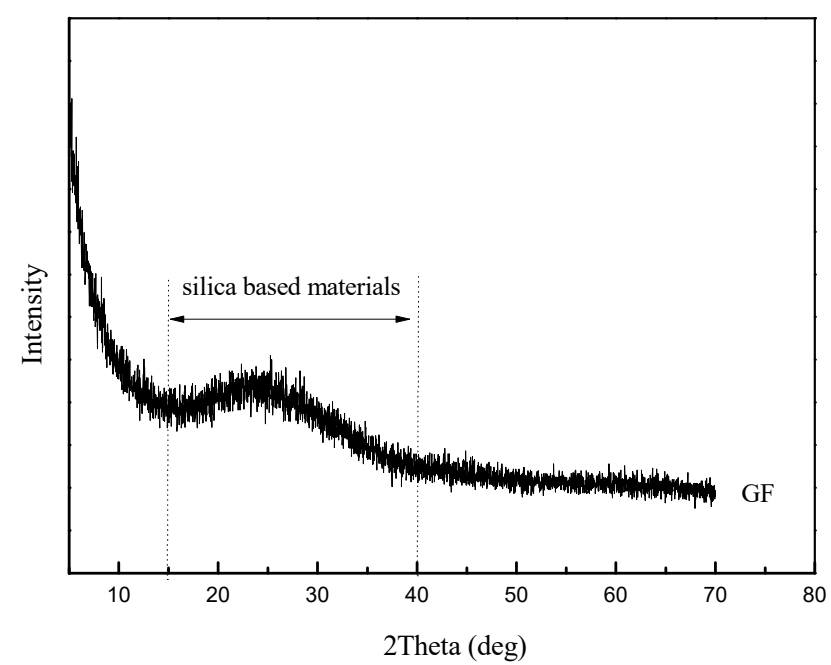

Figure 3. XRD patterns of GF. 


\subsection{Characterization of Composites and Coatings}

\subsubsection{Thickness of the Coatings}

The thickness of the CBPC coatings is shown in Table 3. It is clear that the thickness of the different GCBPC coatings varied from $193 \mu \mathrm{m}$ to $217 \mu \mathrm{m}$ with the increase of GF particles, while the thickness of the CBPC coating was $186 \mu \mathrm{m}$. The coating thicknesses showed a little bit of increase, with regard to the standard deviation of the thickness measurement. The difference in thickness is not enough to affect the corrosion resistance of the coatings.

Table 3. Thickness of phosphate ceramic coatings after curing.

\begin{tabular}{cccccc}
\hline & CBPC & GCBPC0 & $\begin{array}{c}\text { Coatings } \\
\text { GCBPC5 }\end{array}$ & GCBPC10 & GCBPC15 \\
\hline Thickness $(\mu \mathrm{m})$ & 186 & 193 & 201 & 210 & 217 \\
Standard deviation & 0.3 & 0.2 & 0.2 & 0.3 & 0.2 \\
\hline
\end{tabular}

\subsubsection{XRD}

The results obtained from the XRD patterns of the phosphate ceramic coatings are shown in Figure 4. In the case of the CBPC, only $\mathrm{Al}_{2} \mathrm{O}_{3}$ and $\mathrm{AlPO}_{4}$ phase were present. While the unreacted $\mathrm{Al}_{2} \mathrm{O}_{3}, \mathrm{MgO}$ phase and the reacted $\mathrm{AlPO}_{4}, \mathrm{Mg}_{3}\left(\mathrm{PO}_{4}\right)_{2}$ phase was identified in GCBPCs. A new bonding phase $\left(\mathrm{Mg}_{3}\left(\mathrm{PO}_{4}\right)_{2}\right)$ can be found, which may benefit the structural and anti-corrosion properties of the phosphate ceramic coatings, as it has fine needle-like crystals [15]. The new bonding phase was the reaction product of magnesia and MAP solution. $\mathrm{MgO}$ can fully react with MAP solutions in the current pastes, so only the product of $\mathrm{Mg}_{3}\left(\mathrm{PO}_{4}\right)_{2}$ and its XRD peaks remain in the GCBPCs. The main binding phase in the phosphate ceramic coatings originates in these reactions of Equations (2) and (3) $[15,32]$. The reason for the higher peak of $\mathrm{Mg}_{3}\left(\mathrm{PO}_{4}\right)_{2}$ in GCBPCs is related to two aspects. Firstly, the product of CBPC materials is largely limited by the solubility of metal oxides, which means the dissolved magnesia can react faster with MAP due to the higher solubility of the magnesia [33]. Secondly, the peak of $\mathrm{AlPO}_{4}$ phase may not be prominent in the presence of magnesia due to the covering of the $\mathrm{Mg}_{3}\left(\mathrm{PO}_{4}\right)_{2}$ [34]. What's more, the results indicate that the phase of the GF did not alter under the heat treatment of the GCBPCs, which did not affect the crystalline phase of others.

$$
\begin{gathered}
\mathrm{Al}_{2} \mathrm{O}_{3}+\mathrm{Al}\left(\mathrm{H}_{2} \mathrm{PO}_{4}\right)_{3} \rightarrow 3 \mathrm{AlPO}_{4}+3 \mathrm{H}_{2} \mathrm{O} \\
3 \mathrm{MgO}+\mathrm{Al}\left(\mathrm{H}_{2} \mathrm{PO}_{4}\right)_{3} \rightarrow \mathrm{AlPO}_{4}+\mathrm{Mg}_{3}\left(\mathrm{PO}_{4}\right)_{2}+3 \mathrm{H}_{2} \mathrm{O}
\end{gathered}
$$

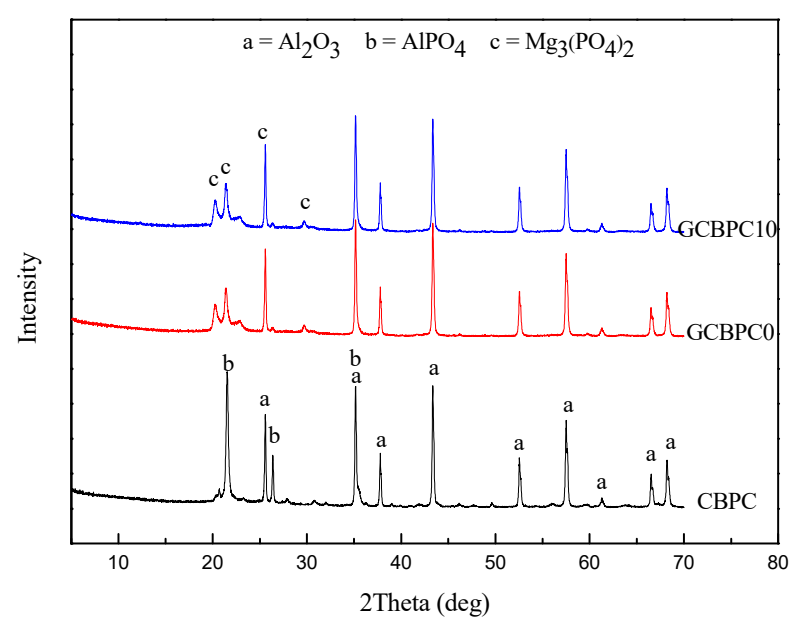

Figure 4. XRD patterns of phosphate ceramic coatings. 


\subsubsection{Thermal Characterization}

To evaluate the effects of the magnesia and the GF additives in the phosphate ceramic materials on the curing behavior, the DSC analysis of the phosphate ceramic materials before curing was conducted, which are shown in Figure 5 . The temperature values of the onset $\left(T_{\text {onset }}\right)$, the peak $\left(T_{p}\right)$, the endset ( $\left.\mathrm{T}_{\text {endset }}\right)$ and the curing enthalpy $(\Delta \mathrm{H})$ are available from the DSC curves, which are predicted in Table 4. All phosphate ceramic materials have only one significant endothermic peak. With the addition of magnesia, the endothermic peak temperature decreased from $228.0^{\circ} \mathrm{C}(\mathrm{CBPC})$ to $126.9^{\circ} \mathrm{C}(\mathrm{GCBPC})$, which approaches the temperature of the maximum dissolution of the bauxite and magnesite [12]. Meanwhile, the endothermic peaks of coatings reinforced with GF are $126.3^{\circ} \mathrm{C}(\mathrm{GCBPC} 5), 125.4^{\circ} \mathrm{C}$ (GCBPC10), $125.2^{\circ} \mathrm{C}(\mathrm{GCBPC} 15)$, respectively.

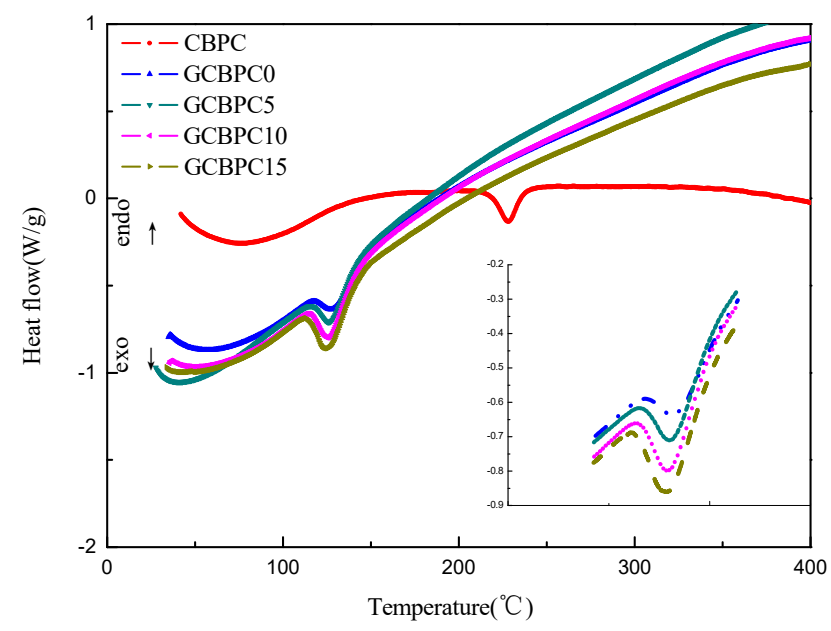

Figure 5. DSC curves of phosphate ceramic materials.

Table 4. Curing parameters from DSC curves.

\begin{tabular}{ccccc}
\hline Sample & $\mathbf{T}_{\text {onset }}\left({ }^{\circ} \mathbf{C}\right)$ & $\mathbf{T}_{\mathbf{p}}\left({ }^{\circ} \mathbf{C}\right)$ & $\mathbf{T}_{\text {endset }}\left({ }^{\circ} \mathbf{C}\right)$ & $\Delta \mathbf{H}(\mathbf{J} / \mathbf{g})$ \\
\hline CBPC & 209.5 & 228.0 & 245.5 & -30.32 \\
GCBPC0 & 118.9 & 126.9 & 153.9 & -37.65 \\
GCBPC5 & 117.8 & 126.3 & 153.3 & -48.30 \\
GCBPC10 & 115.4 & 125.4 & 153.4 & -54.38 \\
GCBPC15 & 113.7 & 125.2 & 153.2 & -56.39
\end{tabular}

where $\mathrm{T}_{\text {onset }}, \mathrm{T}_{\mathrm{p}}, \mathrm{T}_{\text {endset }}$ represents the temperature values of the onset, the peak and the endset, respectively, $\Delta \mathrm{H}$ is the curing enthalpy.

The great changes in curing temperature can be seen clearly with the addition of magnesia [17]. The exothermic peak temperature $\left(\mathrm{T}_{\mathrm{p}}\right)$ of $\mathrm{CBPC}$ is $228^{\circ} \mathrm{C}$, while the GCBPCs are all around $125^{\circ} \mathrm{C}$. Besides, the $\Delta \mathrm{H}$ are $-30.32,-37.65,-48.30,-54.38,-56.39 \mathrm{~J} / \mathrm{g}$, respectively. Therefore, the curing enthalpy of reaction of the phosphate ceramic materials increases with the addition of the magnesia and the GF additives, which emphasizes the higher crosslinking density in the phosphate ceramic materials [35,36].

\subsubsection{SEM}

The typical SEM micrographs of different coating surfaces after curing are shown in Figure 6. The coatings of CBPCs consist of alumina distributed in the MAP binder. The binding phase is produced by the reaction between MAP and the surface of the particles during the curing process. As can be seen, the solidified binder fills the space between the particles. There were differences in the micrograph. The particles of the CBPC coating have an inhomogeneous morphology, the main component of which is $\mathrm{Al}_{2} \mathrm{O}_{3}$, while the particles spread more evenly in GCBPCs, which has a denser 
structure due to the new bonding phase. The result is consistent with the results of DSC. Furthermore, the GF particles on the surface and internal of the coating is shown in Figures 6 and 7. The GF particles and the GCBPC maintain a good adhesion. On the other hand, the GF particles achieve a homogeneous and parallel dispersion on the surface and internal of the coatings.

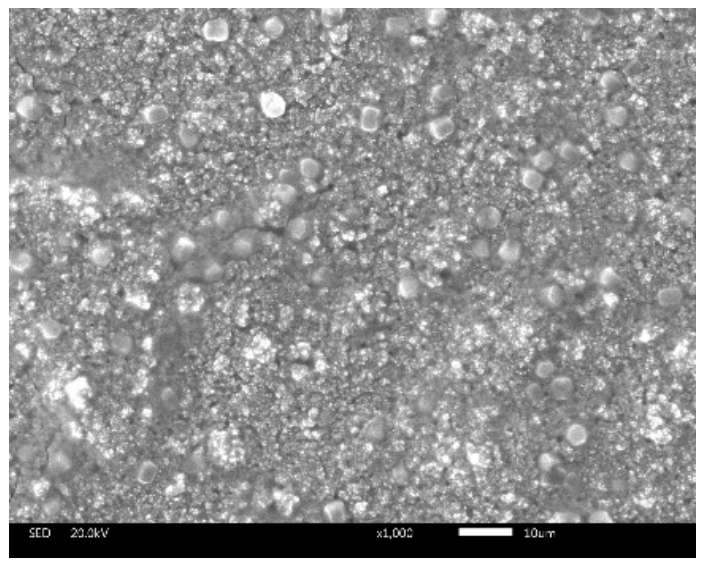

(a)

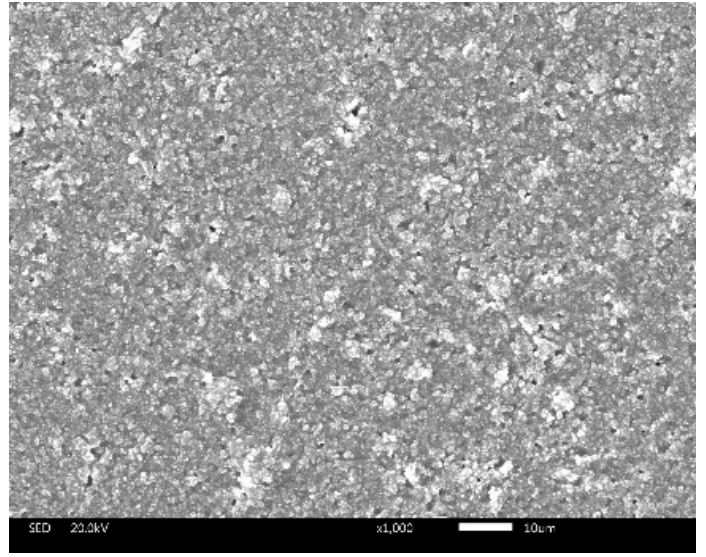

(c)

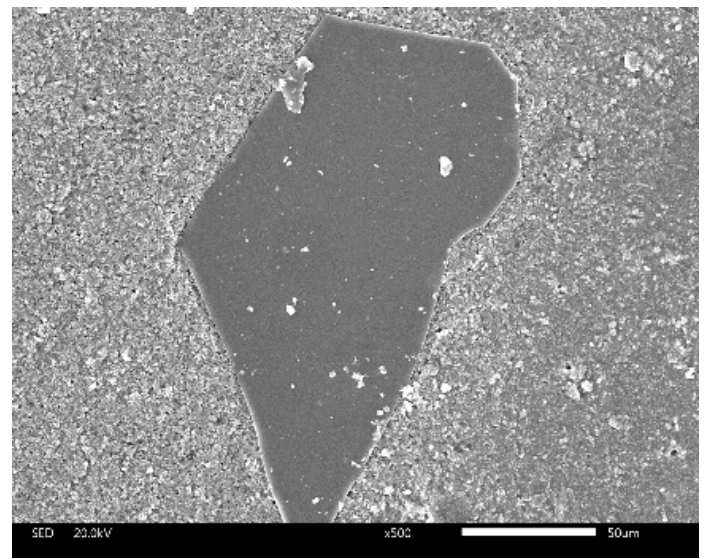

(e)

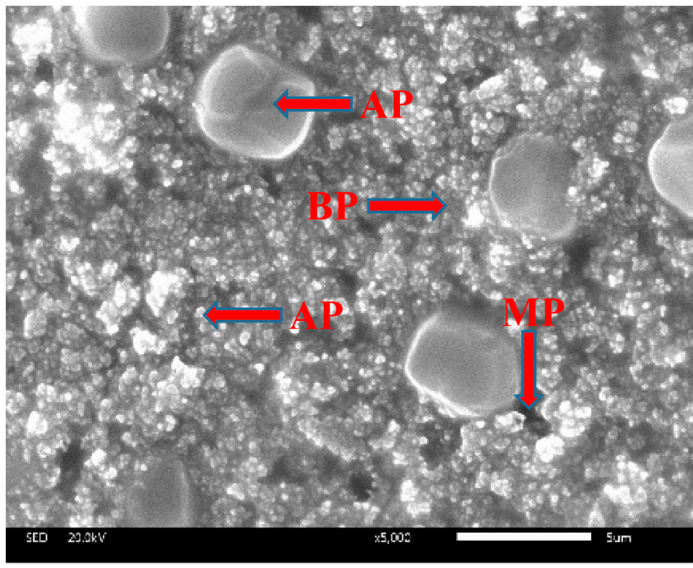

(b)

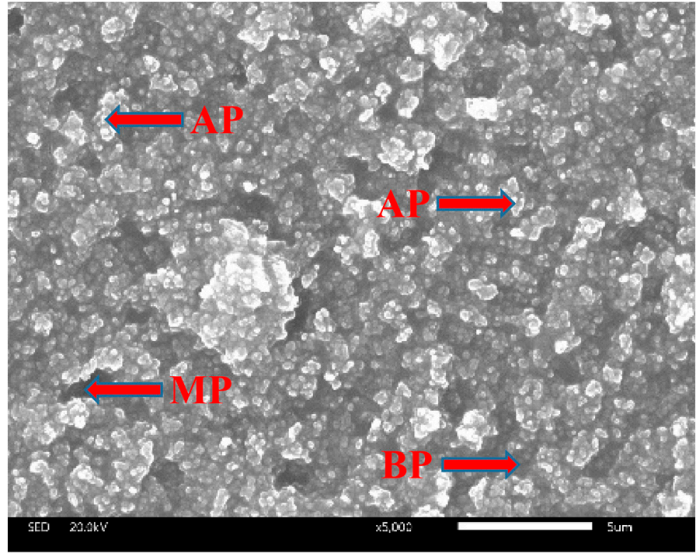

(d)

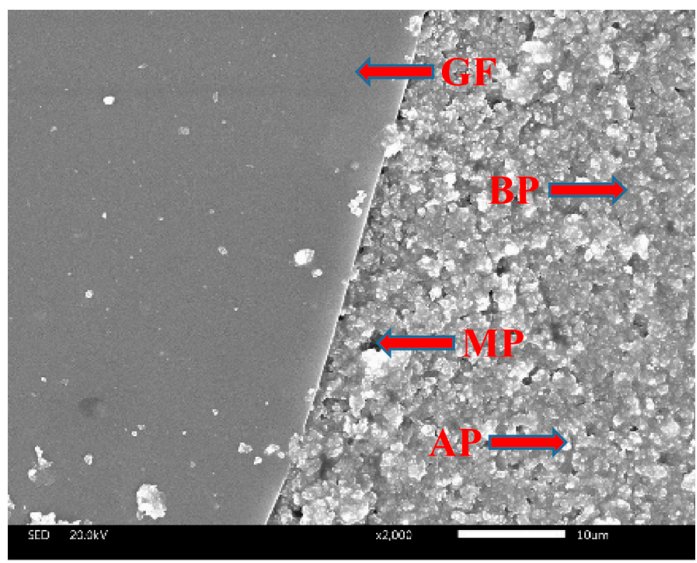

(f)

Figure 6. SEM micrographs of coating surfaces (after curing): (a) $1000 \times \mathrm{CBPC}$; (b) $5000 \times \mathrm{CBPC}$; (c) 1000× GCBPC0; (d) 5000× GCBPC0; (e) 500× GCBPC10; (f) 2000× GCBPC10. Notes: AP (alumina particles), BP (binding phases), MP (micro-porous). 


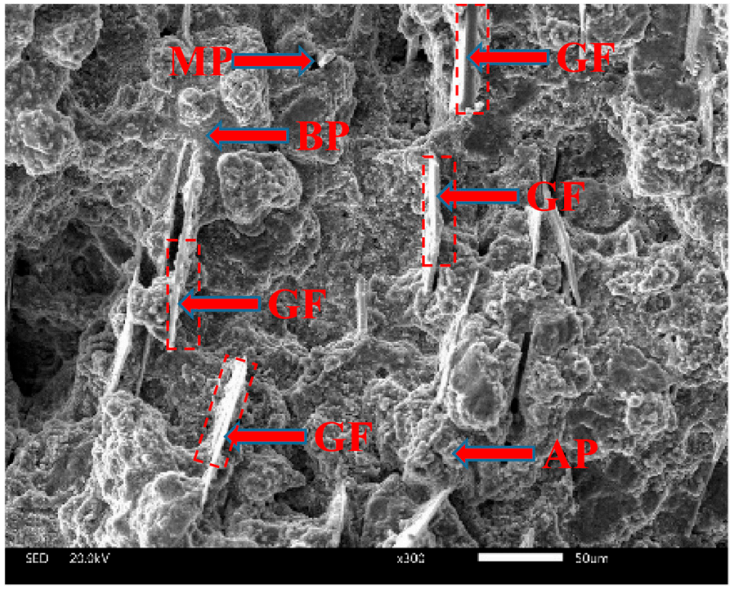

(a)

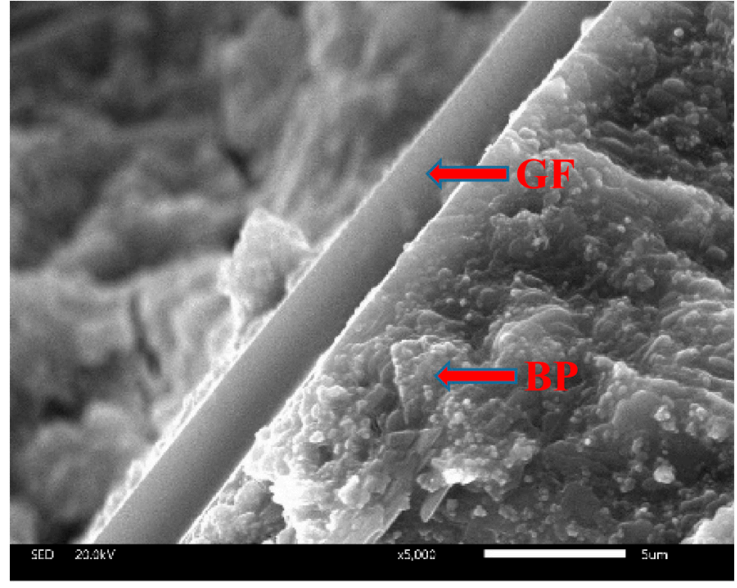

(b)

Figure 7. SEM images of the cross-section in GCBPCs: (a) 300×; (b) 5000×. Notes: AP (alumina particles), BP (binding phases), MP (micro-porous).

\subsection{Anti-Corrosion Performance}

\subsubsection{Potentiodynamic Polarization}

The effect of the magnesia and the GF particles on the corrosion resistance of CBPCs samples was evaluated by using the polarization measurement in $3.5 \mathrm{wt} . \% \mathrm{NaCl}$ solution. Figure 8 illustrates the potentiodynamic polarization data of the uncoated round steel, and the coated different phosphate ceramic samples.

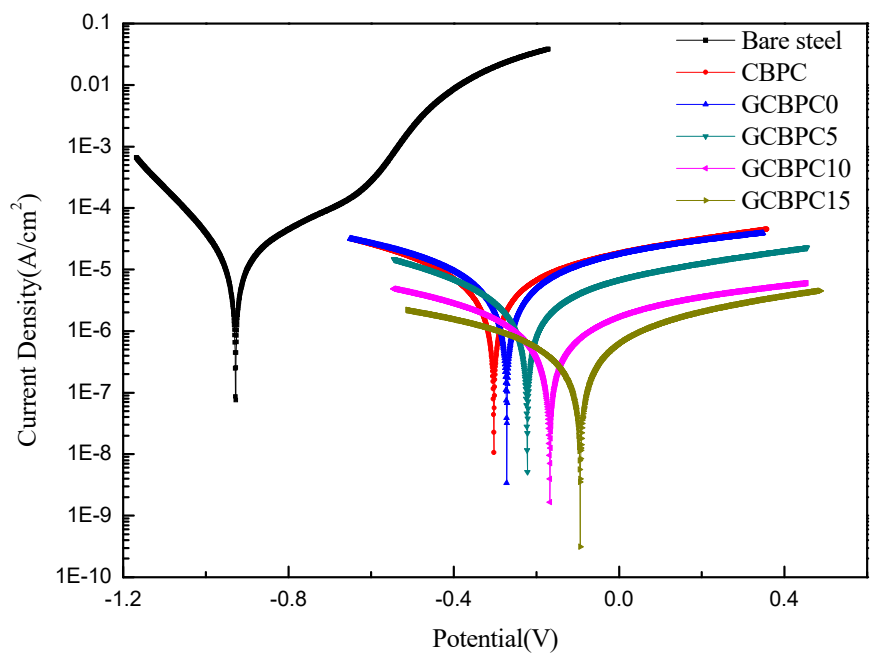

Figure 8. Potentiodynamic polarization curves of phosphate ceramic coatings.

The corresponding electrochemical parameters are shown in Table 5, derived using the Tafel extrapolation method. The results show that the GCBPC0 has a higher $\mathrm{E}_{\text {corr }}$ and a lower $\mathrm{i}_{\text {corr }}$ compared to CBPC, which means the GCBPC0 has a better corrosion resistance than the CBPC. Meanwhile, with the increase of the GF in the GCBPCs, the value of $E_{\text {corr }}$ increases, and the value of $i_{\text {corr }}$ and corrosion rate decreases, indicating that the presence of GF can improve the anti-corrosion performance of the CBPCs [37]. In the GCBPC coating samples, the value of $E_{\text {corr }}$ of GCBPC15 increases from $-0.272 \mathrm{~V}$ of GCBPC0 to $-0.094 \mathrm{~V}$. Additionally, the value of $\mathrm{i}_{\mathrm{corr}}$ and corrosion rate decreases from $7.396 \times 10^{-6} \mathrm{~A} / \mathrm{cm}^{2}, 0.087 \mathrm{~mm} / \mathrm{a}$ to $4.522 \times 10^{-7} \mathrm{~A} / \mathrm{cm}^{2}, 0.005 \mathrm{~mm} / \mathrm{a}$, respectively. The reason for 
this may attributed to the most compact microstructure and the strongest resistance to electrolytes penetration being in GCBPC15. The effective inhibition $\eta$ is calculated from Equation (4) [38].

$$
\eta=\left(1-\frac{\mathrm{i}_{\text {corr }}}{\mathrm{i}_{\text {corr,blank }}}\right) \times 100 \%
$$

where $\mathrm{i}_{\text {corr,blank }}$ is the etching current density of the uncoated sample, while $\mathrm{i}_{\text {corr }}$ represents the corrosion current density of the coated samples. As is well known, the higher the value of $\eta$, the better the anti-corrosion performance may be.

Table 5. Curing parameters based on the potentiodynamic polarization curves.

\begin{tabular}{ccccc}
\hline \multirow{2}{*}{ Sample } & \multicolumn{3}{c}{ Electrochemical Parameter } & \multirow{2}{*}{$\mathbf{~ ( \% )}$} \\
\cline { 2 - 4 } & $\mathbf{E}_{\text {corr }} \mathbf{( V )}$ & $\mathbf{i}_{\text {corr }} \mathbf{( A / \mathbf { c m } ^ { 2 } )}$ & Corrosion Rate $\mathbf{( m m / a )}$ & \\
\hline Bare Steel & -0.928 & $1.503 \times 10^{-5}$ & 0.177 & - \\
CBPC & -0.303 & $8.312 \times 10^{-6}$ & 0.098 & 44.69 \\
GCBPC0 & -0.272 & $7.396 \times 10^{-6}$ & 0.087 & 50.79 \\
GCBPC5 & -0.222 & $3.134 \times 10^{-6}$ & 0.037 & 79.15 \\
GCBPC10 & -0.157 & $1.082 \times 10^{-6}$ & 0.013 & 92.80 \\
GCBPC15 & -0.094 & $4.522 \times 10^{-7}$ & 0.005 & 96.99
\end{tabular}

where $E_{\text {corr }}, i_{\text {corr }}$ represent the corrosion potential and corrosion current density, $\eta$ is the effective inhibition, which is calculated from Equation (4).

\subsubsection{Electrochemical Impedance Spectroscopy}

The EIS method is an effective way to access the anticorrosion property of the CBPCs samples. The Nyquist and Bode plots of the CBPC coated samples immersed for $10 \mathrm{~h}$ in $3.5 \mathrm{wt} . \% \mathrm{NaCl}$ solution are shown in Figure 9. EIS parameters (Table 6) from Nyquist and Bode plots were extracted by using an electrical equivalent circuit $(R(R Q(R Q)))$ to model the experiment. $R_{s}, R_{c}, C P E_{c}, R_{c t}$ and $C P E_{c t}$ represent resistance of solution, resistance of the CBPC coating, nonideal capacity of the CBPC coating, resistance of the charge transfer and nonideal capacity of the double layer, respectively.
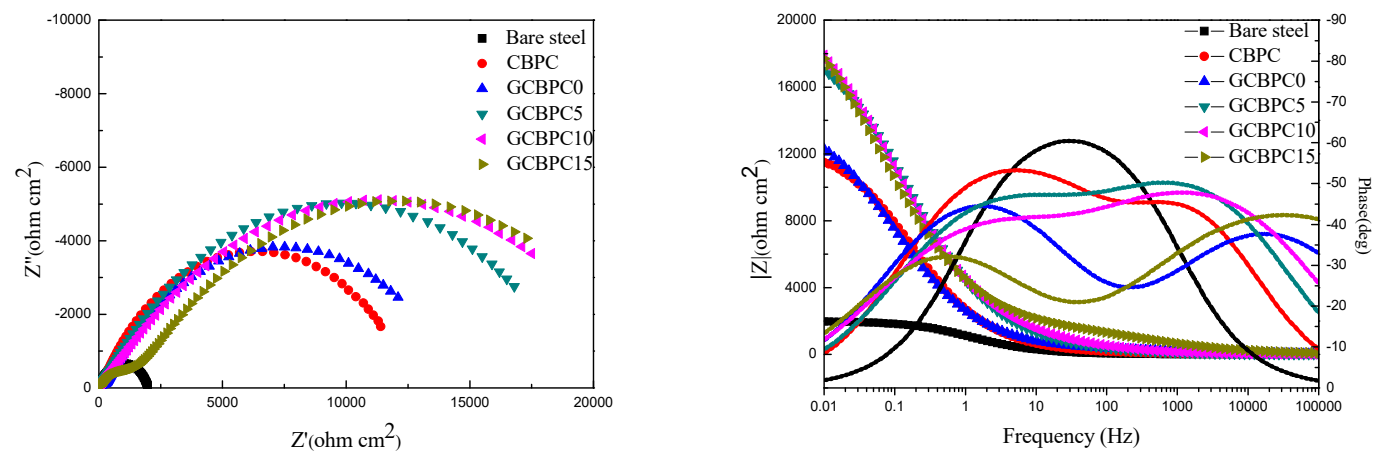

Figure 9. Nyquist and Bode plots of CBPCs.

Table 6. EIS parameters from Nyquist and Bode plots.

\begin{tabular}{cccccccc}
\hline Sample & $\mathbf{R}_{\mathbf{s}}\left(\boldsymbol{\Omega} \cdot \mathbf{c m}^{\mathbf{2}}\right)$ & $\mathbf{R}_{\mathbf{c}}\left(\boldsymbol{\Omega} \cdot \mathbf{c m}^{\mathbf{2}}\right)$ & $\mathbf{C P E}_{\mathbf{c}}\left(\boldsymbol{\Omega} \cdot \mathbf{c m}^{\mathbf{2}}\right)$ & $\mathbf{N}_{\mathbf{c}}$ & $\left.\mathbf{R}_{\mathbf{c t}} \mathbf{(} \mathbf{\Omega} \cdot \mathbf{c m}^{\mathbf{2}}\right)$ & $\mathbf{C P E}_{\mathbf{c t}} \mathbf{( F / \mathbf { c m } ^ { 2 } )}$ & $\mathbf{N}_{\mathbf{c t}}$ \\
\hline Bare Steel & 9.46 & - & - & - & 1989 & $1.4327 \times 10^{-4}$ & 0.75 \\
CBPC & 11.43 & 267 & $4.1701 \times 10^{-5}$ & 0.69 & 12406 & $5.4811 \times 10^{-5}$ & 0.67 \\
GCBPC0 & 11.27 & 371 & $2.0892 \times 10^{-5}$ & 0.57 & 14187 & $9.5405 \times 10^{-5}$ & 0.64 \\
GCBPC5 & 10.98 & 1128 & $3.1458 \times 10^{-5}$ & 0.65 & 18370 & $3.6515 \times 10^{-5}$ & 0.58 \\
GCBPC10 & 10.90 & 1509 & $2.9823 \times 10^{-5}$ & 0.61 & 20619 & $4.785 \times 10^{-5}$ & 0.53 \\
GCBPC15 & 10.88 & 1784 & $9.6835 \times 10^{-6}$ & 0.54 & 20950 & $8.5690 \times 10^{-5}$ & 0.57 \\
\hline
\end{tabular}

where $R_{s}, R_{c}, C P E_{c}, R_{c t}$ and $C P E_{c t}$ represent the resistance of the solution, resistance of the CBPC coating, the nonideal capacity of the CBPC coating, the resistance of charge transfer and the nonideal capacity of the double layer, respectively. 
According to EIS parameters from Table 6, the resistance of the solution $\left(R_{s}\right)$ remains stable, the addition of magnesia improves the anti-corrosion performance of CBPC to a certain extent, as the coating resistance $\left(R_{c}\right)$ and charge transfer resistance $\left(R_{c t}\right)$ increase. Meanwhile, the more GF added within the range of experimental dosage, the better anti-corrosion performance achieved. In addition, the GCBPC15 obtains the strongest anticorrosion property. According to the previous results (DSC, SEM and XRD), two main reasons can be noted for this phenomenon. Firstly, the presence of magnesia contributes to the formation of new phase and increases the compactness of GCBPCs to shield the round steels from the erosion of aggressive electrolyte. Secondly, the parallel distribution of GF particles on the surface and internal of the coating make the electrolyte diffusion path more tortuous.

The comparison of the EIS parameters from different coatings between the previous literature and the results obtained in this research is shown in Table 7. As can be seen, the anti-corrosion property of the epoxy coating is significantly higher than other species of coatings due to the excellent protection against aggressive substances of the polymer matrix. For other types of coatings, GCBPC15 in this paper has better corrosion resistance performance than other coatings, which can mainly be attributed to the compactness of the matrix and the parallel distribution of GF particles.

Table 7. Comparison of the EIS parameters from different coatings.

\begin{tabular}{|c|c|c|c|c|c|c|c|}
\hline Species & $\underset{\left(\Omega \cdot \mathrm{cm}^{2}\right)}{R_{s}}$ & $\begin{array}{c}R_{c} \\
\left(\Omega \cdot \mathrm{cm}^{2}\right)\end{array}$ & $\begin{array}{c}\mathrm{CPE}_{\mathrm{c}} \\
\left(\Omega \cdot \mathrm{cm}^{2}\right)\end{array}$ & $\mathbf{N}_{\mathrm{c}}$ & $\begin{array}{c}R_{\mathrm{ct}} \\
\left(\Omega \cdot \mathrm{cm}^{2}\right)\end{array}$ & $\begin{array}{c}\mathrm{CPE}_{\mathrm{ct}} \\
\left(\mathrm{F} / \mathrm{cm}^{2}\right)\end{array}$ & $\mathbf{N}_{\mathrm{ct}}$ \\
\hline CBPC & 11.43 & 267 & $4.1701 \times 10^{-5}$ & 0.69 & 12406 & $5.4811 \times 10^{-5}$ & 0.67 \\
\hline GCBPC15 & 10.88 & 1784 & $9.6835 \times 10^{-6}$ & 0.54 & 20950 & $8.5690 \times 10^{-5}$ & 0.57 \\
\hline Epoxy [39] & 100 & 28935 & $4.3417 \times 10^{-6}$ & 0.75 & 44523 & $3.8667 \times 10^{-6}$ & 0.22 \\
\hline Galvanized [40] & 10 & 491.6 & $4.0417 \times 10^{-5}$ & 0.80 & 2000 & $3.2378 \times 10^{-5}$ & 0.66 \\
\hline GCBPC0-ZnO [24] & - & 817.2 & $7.2100 \times 10^{-5}$ & 0.64 & 911.7 & $3.8300 \times 10^{-5}$ & 0.79 \\
\hline
\end{tabular}

where $R_{s}, R_{c}, C P E_{c}, R_{c t}$ and $C P E_{c t}$ represent the resistance of the solution, the resistance of the coating, the nonideal capacity of the coating, the resistance of the charge transfer and the nonideal capacity of the double layer, respectively.

\subsection{Corrosion Protection Mechanism}

As is widely known, the initial corrosion is commonly due to the penetration of sufficient $\mathrm{H}_{2} \mathrm{O}, \mathrm{O}_{2}$, $\mathrm{Cl}^{-}$, or their combined effect on the steel $[2,41]$. The corrosion will cease to exist until the penetration is inhibited. For CBPCs, the substrate is protected by the compact coatings, which can retard the substrate corrosion under in cases with $\mathrm{H}_{2} \mathrm{O}, \mathrm{O}_{2}$ and $\mathrm{Cl}^{-}$. The surface microstructures of the CBPC coatings are presented in Figure 7. Compared to GCBPC0, the GF particles are found in phosphate ceramics coatings, as shown in Figures 7 and 8. The reason the GCBPC10 has better anticorrosion performance than GCBPC0 is that the new bonding phase and GF can hinder the permeation pathway of $\mathrm{H}_{2} \mathrm{O}, \mathrm{O}_{2}$ and $\mathrm{Cl}^{-}$and make the permeation more circuitous.

These results indicate that GF-reinforced chemically bonded phosphate ceramic coatings are potentially superior compared to the neat chemically bonded phosphate ceramics in terms of anti-corrosion property. To clarify the anticorrosion performance, a model of GF reinforced chemically bonded phosphate ceramic coating was established. As shown in Figure 10, for CBPC or GCBPC0, aggressive substances such as $\mathrm{H}_{2} \mathrm{O}, \mathrm{O}_{2}$ and $\mathrm{Cl}^{-}$can be passed to the substrate through the diffusion route between the binding phase and the particle. However, the binding phase and the GF can hinder the aggressive substances permeation pathway and make the diffusion route more tortuous in GCBPCs, preventing $\mathrm{H}_{2} \mathrm{O}, \mathrm{O}_{2}$ and $\mathrm{Cl}^{-}$from engaging the substrate effectively. 

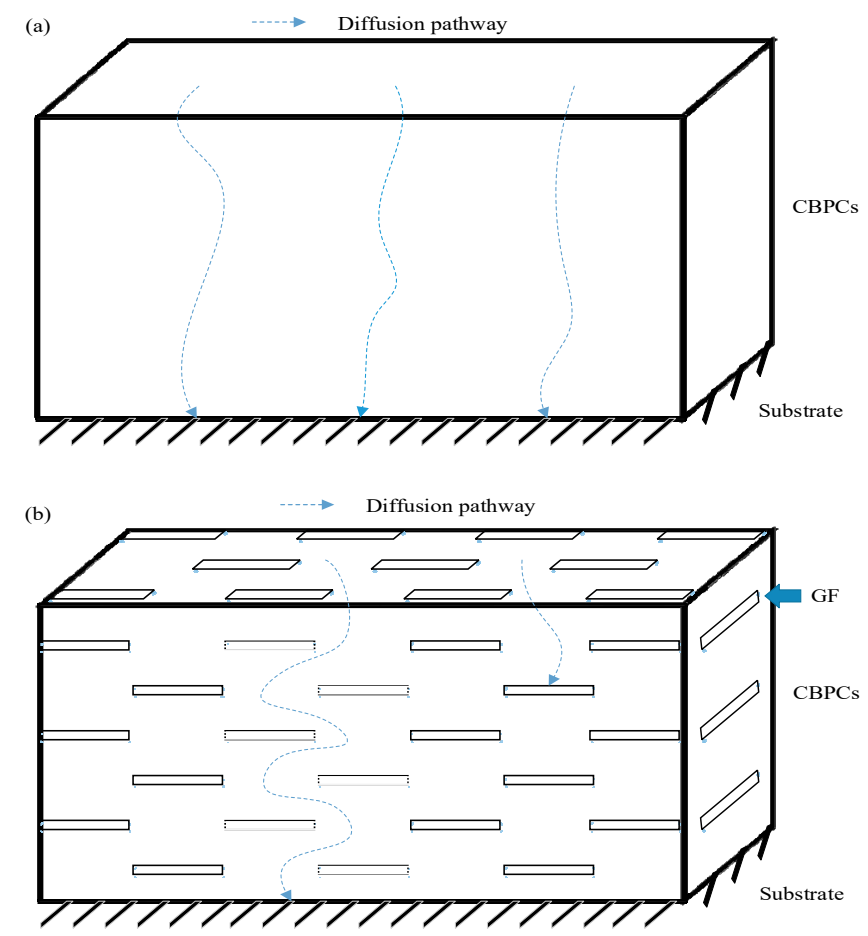

Figure 10. Schematic diagram of the anti-corrosion mechanism in (a) CBPCs and (b) GCBPCs.

\section{Conclusions}

The glass flake-reinforced chemically bonded phosphate ceramic coatings were prepared on round steel. The crystalline phase, curing behavior, micromorphology and electrochemical performance of the coating were studied. The main conclusions can be obtained as follows:

(1) With the addition of magnesia, a new bonding phase $\left(\mathrm{Mg}_{3}\left(\mathrm{PO}_{4}\right)_{2}\right)$ can be formed, which can help the GCBPCs obtain a more compact and denser structure. Meanwhile, The GF particles have a good adhesion with GCBPC and achieve a homogeneous and parallel dispersion on the surface and internal of the coatings.

(2) The effect of the magnesia and the GF additives on curing behavior is obvious; the heat of reaction of the phosphate ceramic materials increases, which emphasizes the higher crosslinking density in the phosphate ceramic materials.

(3) The phosphate ceramic coatings with the magnesia have a higher impedance value compared with the neat phosphate ceramic coating, while the highest impedance value is acquired with increase content of GF. It is found that GCBPC0 has a smaller particle size and a denser structure due to the new bonding phase compared with CBPC, and GF is distributed parallel on the surface and internal of the GCBPCs homogeneously. The corrosion mechanism is mainly contributed by the new bonding phase and GF, which can hinder the permeation pathway and make the permeation more circuitous.

Author Contributions: Conceptualization and Methodology, G.Y. and W.Y.; Validation, G.Y. and T.S.; Resources, T.S.; Data Curation, G.W.; Writing—Original Draft Preparation, G.Y.; Writing—Review \& Editing, M.W. and X.L.

Funding: This study was financially supported by the National Key Research and Development Program of China (No. 2017YFB0310905), Yang Fan Innovative \& Entrepreneurial Research Team Project (No. 201312C12), and the 111 Project (No. B18038).

Conflicts of Interest: The authors declare no conflict of interest. 


\section{References}

1. Yan, D.; Reis, S.; Tao, X.; Chen, G.; Brow, R.K.; Koenigstein, M. Effect of chemically reactive enamel coating on bonding strength at steel/mortar interface. Constr. Build. Mater. 2012, 28, 512-518. [CrossRef]

2. Zhu, X.; Chen, Z.; Wang, H.; Chen, Y.; Xu, L. Probabilistic Generalization of a Comprehensive Model for the Deterioration Prediction of RC Structure under Extreme Corrosion Environments. Sustainability 2018, 10, 3051. [CrossRef]

3. Selvaraj, R.; Selvaraj, M.; Iyer, S. Studies on the evaluation of the performance of organic coatings used for the prevention of corrosion of steel rebars in concrete structures. Prog. Org. Coat. 2009, 64, 454-459. [CrossRef]

4. Kobayashi, K.; Takewaka, K. Experimental studies on epoxy coated reinforcing steel for corrosion protection. Int. J. Cem. Compos. Light. Concr. 1984, 6, 99-116. [CrossRef]

5. Končan Volmajer, N.; Steinbücher, M.; Berce, P.; Venturini, P.; Gaberšček, M. Electrochemical Impedance Spectroscopy Study of Waterborne Epoxy Coating Film Formation. Coatings 2019, 9, 254. [CrossRef]

6. Pour-Ali, S.; Dehghanian, C.; Kosari, A. Corrosion protection of the reinforcing steels in chloride-laden concrete environment through epoxy/polyaniline-camphorsulfonate nanocomposite coating. Corros. Sci. 2015, 90, 239-247. [CrossRef]

7. Cheng, A.; Huang, R.; Wu, J.; Chen, C. Effect of rebar coating on corrosion resistance and bond strength of reinforced concrete. Constr. Build. Mater. 2005, 19, 404-412. [CrossRef]

8. Tang, F.; Chen, G.; Brow, R.K.; Volz, J.S.; Koenigstein, M.L. Corrosion resistance and mechanism of steel rebar coated with three types of enamel. Corros. Sci. 2012, 59, 157-168. [CrossRef]

9. Liu, Y.; Bian, D.; Zhao, Y.; Wang, Y. Influence of curing temperature on corrosion protection property of chemically bonded phosphate ceramic coatings with nano-titanium dioxide reinforcement. Ceram. Int. 2019, 45, 1595-1604. [CrossRef]

10. Brown, M.C. Corrosion protection service life of epoxy coated reinforcing steel in virginia bridge decks. Diss. Abstr. Int. 2002, 63, 3825.

11. Kayali, O.; Yeomans, S.R. Bond of ribbed galvanized reinforcing steel in concrete. Cem. Concr. Compos. 2000, 22, 459-467. [CrossRef]

12. Arenas, M.A.; Casado, C.; Nobel-Pujol, V.; De Damborenea, J. Influence of the conversion coating on the corrosion of galvanized reinforcing steel. Cem. Concr. Compos. 2006, 28, 267-275. [CrossRef]

13. Wagh, A.S.; Jeong, S.Y. Chemically Bonded Phosphate Ceramics: I, A Dissolution Model of Formation. J. Am. Ceram. Soc. 2003, 86, 1838-1844. [CrossRef]

14. Formosa, J.; Chimenos, J.M.; Lacasta, A.M.; Niubó, M. Interaction between low-grade magnesium oxide and boric acid in chemically bonded phosphate ceramics formulation. Ceram. Int. 2012, 38, 2483-2493. [CrossRef]

15. Wagh, A.S. Chemically Bonded Phosphate Ceramics, Twenty-First Century Materials with Diverse Applications, 2nd ed.; Elsevier: Naperville, IL, USA, 2016.

16. Han, H.-J.; Kim, D.-P. Studies on Curing Chemistry of Aluminum-Chromium-Phosphates as Low Temperature Curable Binders. J. Sol-Gel Sci. Technol. 2003, 26, 223-228. [CrossRef]

17. Hong, L.Y.; Han, H.J.; Ha, H.; Lee, J.Y.; Kim, D.P. Development of Cr-free aluminum phosphate binders and their composite applications. Compos. Sci. Technol. 2007, 67, 1195-1201. [CrossRef]

18. Yang, X.; Huang, Y.; Zhang, J.; Cao, H. Preparation and properties of phosphate base heat-resisting composites. Chem. Adhes. 2005, 27, 67-70.

19. Chen, D.; He, L.; Shang, S. Study on aluminum phosphate binder and related $\mathrm{Al}_{2} \mathrm{O}_{3}-\mathrm{SiC}$ ceramic coating. Mater. Sci. Eng. A 2003, 348, 29-35. [CrossRef]

20. Moorlag, C.; Yang, Q.; Troczynski, T.; Bretherton, J.; Fyfe, C. Aluminum Phosphates Derived from Alumina and Alumina-Sol-Gel Systems. J. Am. Ceram. Soc. 2004, 87, 2064-2071. [CrossRef]

21. Hawthorne, H.; Neville, A.; Troczynski, T.; Hu, X.; Thammachart, M.; Xie, Y.; Fu, J.; Yang, Q. Characterization of chemically bonded composite sol-gel based alumina coatings on steel substrates. Surf. Coat. Technol. 2004, 176, 243-252. [CrossRef]

22. Vippola, M.; Ahmaniemi, S.; Keränen, J.; Vuoristo, P.; Lepistö, T.; Mäntylä, T.; Olsson, E. Aluminum phosphate sealed alumina coating: characterization of microstructure. Mater. Sci. Eng. A 2002, 323, 1-8. [CrossRef]

23. Wagh, A.; Drozd, V. Inorganic Phosphate Corrosion Resistant Coatings. U.S. Patent US20130139930A1, 6 June 2013. 
24. Bian, D.; Zhao, Y. Preparation and corrosion mechanism of graphene-reinforced chemically bonded phosphate ceramics. J. Sol-Gel Sci. Technol. 2016, 80, 30-37. [CrossRef]

25. Ding, Z.; Li, Y.Y.; Lu, C.; Liu, J. An Investigation of Fiber Reinforced Chemically Bonded Phosphate Ceramic Composites at Room Temperature. Materials 2018, 11, 858. [CrossRef] [PubMed]

26. Lokuge, W.; Aravinthan, T. Effect of fly ash on the behaviour of polymer concrete with different types of resin. Mater. Des. 2013, 51, 175-181. [CrossRef]

27. Momber, A.; Irmer, M.; Glück, N. Performance characteristics of protective coatings under low-temperature offshore conditions. Part 1: Experimental set-up and corrosion protection performance. Cold Reg. Sci. Technol. 2016, 127, 76-82. [CrossRef]

28. Chi, S.; Park, J.; Shon, M. Study on cavitation erosion resistance and surface topologies of various coating materials used in shipbuilding industry. J. Ind. Eng. Chem. 2015, 26, 384-389. [CrossRef]

29. Du, Y.; Sun, J.; Yang, H.; Yan, L. Recovery of gallium in the alumina production process from high-alumina coal fly ash. Rare Met. Mater. Eng. 2016, 45, 1893-1897.

30. Barbhuiya, S.; Choudhury, M.I. Nanoscale Characterization of Glass Flake Filled Vinyl Ester Anti-Corrosion Coatings. Coatings 2017, 7, 116. [CrossRef]

31. Manna, J.; Roy, B.; Sharma, P. Efficient hydrogen generation from sodium borohydride hydrolysis using silica sulfuric acid catalyst. J. Power Sources 2015, 275, 727-733. [CrossRef]

32. Deng, S.; Wang, C.; Zhou, Y.; Huang, F.; Du, L. Preparation and Characterization of Fiber-Reinforced Aluminum Phosphate/Silica Composites with Interpenetrating Phase Structures. Int. J. Appl. Ceram. Technol. 2010, 8, 360-365. [CrossRef]

33. Soudée, E.; Pera, J. Mechanism of setting reaction in magnesia-phosphate cements. Cem. Concr. Res. 2000, 30, 315-321. [CrossRef]

34. Will, G. Powder Diffraction: The Rietveld Method and the Two Stage Method to Determine and Refine Crystal Structures from Powder Diffraction Data; Springer Science \& Business Media: Bonn, Germany, 2006.

35. Karasinski, E.; Da Luz, M.; Lepienski, C.M.; Coelho, L. Nanostructured coating based on epoxy/metal oxides: Kinetic curing and mechanical properties. Thermochim. Acta 2013, 569, 167-176. [CrossRef]

36. Sari, M.G.; Saeb, M.R.; Shabanian, M.; Khaleghi, M.; Vahabi, H.; Vagner, C.; Zarrintaj, P.; Khalili, R.; Paran, S.M.R.; Ramezanzadeh, B.; et al. Epoxy/starch-modified nano-zinc oxide transparent nanocomposite coatings: A showcase of superior curing behavior. Prog. Org. Coat. 2018, 115, 143-150. [CrossRef]

37. Romano, A.-P.; Olivier, M.-G.; Vandermiers, C.; Poelman, M. Influence of the curing temperature of a cataphoretic coating on the development of filiform corrosion of aluminium. Prog. Org. Coat. 2006, 57, 400-407. [CrossRef]

38. Shao, F.; Yang, K.; Zhao, H.; Liu, C.; Wang, L.; Tao, S. Effects of inorganic sealant and brief heat treatments on corrosion behavior of plasma sprayed $\mathrm{Cr}_{2} \mathrm{O}_{3}-\mathrm{Al}_{2} \mathrm{O}_{3}$ composite ceramic coatings. Surf. Coat. Technol. 2015, 276, 8-15. [CrossRef]

39. Golabadi, M.; Aliofkhazraei, M.; Toorani, M.; Rouhaghdam, A.S. Corrosion and cathodic disbondment resistance of epoxy coating on zinc phosphate conversion coating containing $\mathrm{Ni}^{2+}$ and $\mathrm{Co}^{2+}$. J. Ind. Eng. Chem. 2017, 47, 154-168. [CrossRef]

40. Hosseini, M.; Ashassi-Sorkhabi, H.; Ghiasvand, H.A.Y. Corrosion Protection of Electro-Galvanized Steel by Green Conversion Coatings. J. Rare Earths 2007, 537-543. [CrossRef]

41. Chang, C.H.; Huang, T.C.; Peng, C.W.; Yeh, T.C.; Lu, H.I.; Hung, W.I.; Weng, C.J.; Yang, T.I.; Yeh, J.M. Novel anticorrosion coatings prepared from polyaniline/graphene composites. Carbon 2012, 50, 5044-5051. [CrossRef]

(C) 2019 by the authors. Licensee MDPI, Basel, Switzerland. This article is an open access article distributed under the terms and conditions of the Creative Commons Attribution (CC BY) license (http://creativecommons.org/licenses/by/4.0/). 